\title{
A Comprehensive Quantitative Assay for Amine Transaminases
}

\author{
Ryan Cairns, ${ }^{\neq[a]}$ Andrew Gomm, ${ }^{\neq[a]}$ Christopher Peel, ${ }^{[a]}$ Michael Sharkey ${ }^{*[a]}$ and Elaine O'Reilly ${ }^{*[a, b]}$
}

\begin{abstract}
The development of effective high-throughput screening assays has contributed greatly to the wealth of designer enzymes available, by enabling rapid identification of desired variants from large mutant libraries. Here, we report a general and operationally simple end-point assay for transaminases that enables the screening of both amine donors and acceptors in liquid phase. The spectrophotometric-based screen exploits the amine donor 2aminoethylaniline (2-AEA) and relies on reaction of in situ generated indole with Ehrlich's reagent. The assay has also been adapted to allow screening in the reverse direction by addition of indole and subsequent spectrophotometric analysis. Importantly, the screen provides qualitative information on the enantio-preference of the individual biocatalysts. To increase the assay throughput, an engineered expression strain ( $E$. coli BL21(DE3) $\Delta$ tnaA) lacking tryptophanase activity, was generated to enable reliable and direct evaluation of individual colonies arrayed on agar plates.
\end{abstract}

The development and application of enzymes for the sustainable production of (chiral) molecules remains a thriving area of research. ${ }^{[1]}$ Access to efficient, low-cost synthetic gene synthesis and DNA sequencing, as well as major advances in protein engineering, have led to the wealth of 'designer biocatalysts' that have been developed in academic and industrial laboratories. Directed evolution in particular has enabled rapid tailoring of enzymes, providing catalysts with altered substrate scope, stereoselectivity and enhanced stability, ${ }^{[2]}$ and making it possible to consider enzymes alongside more traditional catalysts when designing routes to complex molecules. The directed evolution strategy mimics natural evolution and involves subjecting a gene to iterative rounds of mutagenesis followed by selection, until a catalyst with the desired activity is identified. ${ }^{[3]}$ The success of the approach relies heavily on efficient screening strategies to allow detection of improved variants, and the design of such screens has been the subject of much research. ${ }^{[4]}$ The significant impact that directed evolution has had on the development of synthetically useful enzymes and the consequent expansion of the catalytic toolbox has recently been recognized with the award of the Nobel Prize in Chemistry. ${ }^{[5]}$

The prevalence of chiral amines in natural products, (agro)chemicals and active pharmaceutical ingredients [1b, 1d, 6] has led to enormous interest in the engineering and evolution of amine transaminases (ATAs) for the production of such high-

\footnotetext{
[a] Mr. R. Cairns, Dr. A. Gomm, Mr. C. Peel, Dr. M. Sharkey,

Dr. E. O'Reilly

School of Chemistry

University of Nottingham

University Park

Nottingham, NG7 2RD, UK

E-mail: elaine.oreilly@ucd.ie michael.sharkey@nottingham.ac.uk

[b] Current address: School of Chemistry

University College Dublin

Belfield, Dublin 4, Ireland

[‡] These authors contributed equally and names are listed alphabetically.
}

Supporting information for this article is given via a link at the end of the document. value compounds. These pyridoxal-5'-phosphate dependent enzymes are capable of catalyzing the conversion of aldehydes and pro-chiral ketones to the corresponding (chiral) amines. ${ }^{[1 \mathrm{~b}, 6]}$ Although wild-type (WT) ATAs tend to have a somewhat narrow substrate scope, there are many impressive examples of enzyme engineering that have provided catalysts with a significantly broader substrate range and with suitable properties for industrial application. ${ }^{[1 \mathrm{~b}, 6 \mathrm{a}-\mathrm{b}, 7]}$ However, assay development with ATAs presents a particular challenge, as a primary amine and carbonyl compound are both consumed and produced during the reaction. This often means that the design of a general, substrate independent assay to aid engineering is not straightforward.

To simplify engineering, a number of enzymatic and nonenzymatic assays have been developed that focus on monitoring the formation of the product or co-product. Enzymatic cascades, exploiting amino acid dehydrogenase ${ }^{[8]}$ and amino acid oxidases in combination with horseradish peroxidase, ${ }^{[9]}$ have been successfully developed to detect specific amino or carbonyl products. However, despite the elegance of many of these approaches, the use of multiple enzymes can complicate assays and limit their practical application. Non-enzymatic assays have also been developed, which rely on spectroscopic, ${ }^{[10]}$ fluorescent ${ }^{[11]}$ or colorimetric ${ }^{[12]}$ detection of (co)products. One of the most established and successful assays relies on the spectrophotometric detection of acetophenone, when the widely accepted amine donor, $\alpha$-methylbenzylamine, is employed. ${ }^{[10]}$ However, the assay has a number of drawbacks, which means the development of an alternative screening strategy is extremely important. Firstly, as the protein contributes to the initial absorbance, there are limitations to the amount of protein that can be used in this assay. Secondly, the screen is typically only used for assessing the conversion of $\alpha$-methylbenzylamine to acetophenone in the presence of low absorbing amine acceptors and does not routinely allow screening of a broad range of UV active acceptors or of alternative amine donors. Furthermore, successful application of this assay for large library design and evaluation often relies on expensive robotics platforms and cannot be used for assessing colonies arrayed on agar plates.

In an effort to overcome some of the challenges associated with the 'acetophenone assay', our group previously reported the application of the 'smart' diamine donor, $o$-xylylenediamine, which upon transamination, forms an unstable isoindole coproduct that rapidly polymerizes. ${ }^{[13]}$ The dark polymer produced provides a useful method for detecting ATA activity and has been demonstrated to be effective for both liquid and solid-phase assays. ${ }^{[13,14]}$ However, while the formation of this insoluble polymer provides a useful qualitative assay, it prevents quantitative analysis and therefore its application is limited. Although a number of the assays discussed above can be used to identify catalysts with the desired activity and stereoselectivity, none represent a general approach for the quantitative detection of novel amine donors and ketone acceptors in both liquid and solid phase. Here, we report an operationally simple and accurate quantitative assay that can be used to identify novel amine or carbonyl substrates in liquid phase, and also allows identification of enzymes with the desired stereoselectivity. The broad utility of the assay relies on the spectrophotometric monitoring of in situ produced or exogenously added indole (1), which reacts with 
Ehrlich's reagent ${ }^{[15]}$ to produce $\beta$-bis(indolyl)methane 3 (Scheme 1). To increase the utility and throughput of the assay, we have also developed an engineered $E$. coli strain that can be employed for direct colony-based screening.

2-Aminoethylaniline (2-AEA) (4) (Table 1), was synthesized from commercially available (2-nitrophenyl)acetonitrile (see SI). It was envisaged that employing (4) as an amine donor would lead to an indole coproduct that could be exploited for high-throughput screening. While indole itself is not colored and it is not possible to follow its formation spectrophotometrically under biotransformation conditions, it readily reacts with Ehrlich's reagent to produce compound (3). ${ }^{[15,16]}$ This reagent, containing 4-DMAB (2), concentrated $\mathrm{HCl}$ and alcohol, was historically used to test for the presence of indole in bacterial cultures, ${ }^{[16]}$ and many variations on the original conditions have since been employed. ${ }^{[15}$ 17]

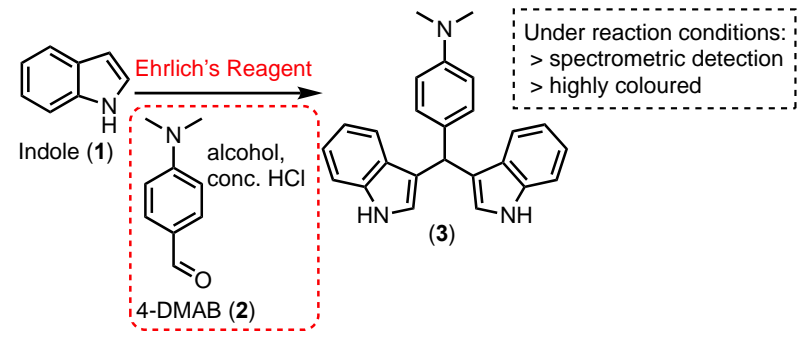

14-UIVIAB (Z) :

Scheme 1. Reaction of indole (1) with 4-dimethylaminobenzaldehyde (4-DMAB) (2), a key component in Ehrlich's reagent, to give (3).

Initial efforts focused on investigating whether 2-AEA (4) was readily accepted as an amine donor by $(S)$-selective $3 \mathrm{HMU}$ and commercially available ATA-113 (Table 1). Four ketones (58) were selected to evaluate this transformation. The highest conversions were achieved with ketone (7), where 2 equivalents of 2-AEA were sufficient to reach a conversion of $69 \%$ with ATA113 and $23 \%$ for $3 \mathrm{HMU}$. ${ }^{[18]}$

Table 1. Conversion of ketones (5-8) $(5 \mathrm{mM})$ to the corresponding amines in the presence of 2-AEA (10 $\mathrm{mM})$.
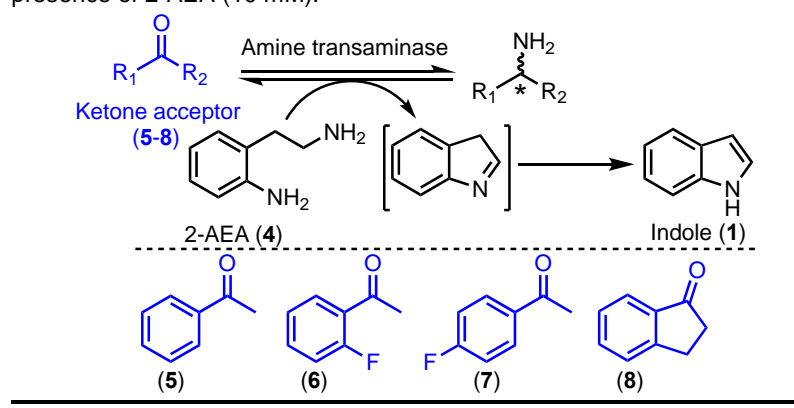

\begin{tabular}{ccccc}
\hline Entry & Ketone & Enzyme & $\begin{array}{c}\text { Equivalents } \\
(\mathbf{4})\end{array}$ & \% Conv. \\
\hline 1 & $\mathbf{5}$ & ATA113 & 2 & 8 \\
2 & $\mathbf{6}$ & ATA113 & 2 & 62 \\
3 & $\mathbf{7}$ & ATA113 & 2 & 69 \\
4 & $\mathbf{8}$ & ATA113 & 2 & $<5$ \\
5 & $\mathbf{7}$ & 3HMU & 2 & 23 \\
\hline
\end{tabular}

Conversion is based on the consumption of starting material.
Next, we focused on the development of a quantitative liquid-phase assay that would enable rapid identification of TAs with activity towards ketones, by exploiting 2-AEA in combination with Ehrlich's reagent. Biotransformations of (4fluorophenyl)acetone (7), catalyzed by ATA-113 and 3HMU, were monitored at various time points over a 24 hour period, to ensure that the assay was quantitative over a wide range of conversions (Figure 1). Controls were used to generate a standard curve, where absorbance directly corresponds to conversion (see SI). Inclusion of these controls alongside the biotransformations was necessary to generate a reliable standard curve and enable conversions to be accurately calculated. Plate 1 shows the biotransformations of ketone (7) with ATA-113. Color intensity increases across columns A-F as the biotransformation progresses, due to the increasing concentration of indole available to react with 4-DMAB. The same trend is apparent in plate 2, containing WT 3HMU. However, the lower color intensity across the wells suggests a significantly lower conversion. Spectrophotometric analysis supported this trend and allowed the calculation of conversion values (Table 2). To confirm the reliability of the conversions predicted from the spectrometer, the same biotransformations were also analyzed by GC/FID (Table 2). Even at low conversions, the two independently calculated values across all time point are closely comparable.

Compound $\mathbf{3}$ was synthesized chemically and compared to the product isolated from a typical biotransformation and subsequent reaction with Ehrlich's reagent. While NMR data confirms that compound $\mathbf{3}$ is formed under these reaction conditions, the exact nature of the molecule giving rise to the intense color and strong spectrophotometric signal is not fully understood and has not been investigated in this work.

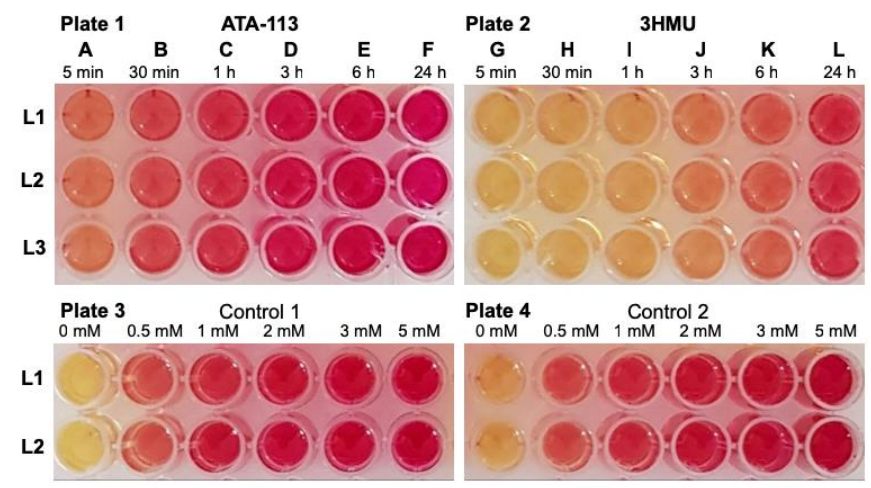

Figure 1. Acceptor screen: biotransformations with (4-fluorophenyl)acetone (7) $(5 \mathrm{mM})$ and 2-AEA (15 mM) at various time points, developed using Ehrlich's reagent. Plate $1 \& 2$ : (4-fluorophenyl)acetone $(7)(5 \mathrm{mM}), 2-A E A(15 \mathrm{mM})$, ATA$113(2.5 \mathrm{mg} / \mathrm{mL})$ or $3 \mathrm{HMU}(2 \%$ lysate). Plate 3 \& 4 : same as plate 1 \& 2 but enzyme omitted and indole added $(0 \mathrm{mM}-5 \mathrm{mM})$. L1-3 are replicates. Control 1 and 2 differ only in reaction setup for the commercial and WT enzyme. See SI for details.

Table 2. Acceptor screen: Conversion of (4-fluorophenyl)acetone (7) (5 mM) to the corresponding amine using ATA-113 or 3HMU, in the presence of 2-AEA (15 $\mathrm{mM})$, as determined by colorimetric assay and GC-FID

\begin{tabular}{cccc}
\hline Entry & $\begin{array}{c}\text { Reaction } \\
\text { Time }(\mathrm{h})\end{array}$ & $\begin{array}{c}\text { Abs. } \\
\% \text { conv. }\end{array}$ & $\begin{array}{c}\text { GC } \\
\% \text { conv. }\end{array}$ \\
\hline ATA-113 & & 19 & 25 \\
1 & 1 & 38 & 43 \\
2 & 3 & 60 & 64 \\
3 & 6 & 81 & 84 \\
4 & 24 & & \\
3HMU & & $<5$ & $<5$ \\
5 & 1 & &
\end{tabular}




\begin{tabular}{cccc}
6 & 3 & $<5$ & $<5$ \\
7 & 6 & $<5$ & 6 \\
8 & 24 & 26 & 23 \\
\hline
\end{tabular}

GC conversion is based on the disappearance of starting material. See SI for details

It became apparent that the Ehrlich test could be reversed to develop a useful amine donor screen, if 4-DMAB were employed as a universal amine acceptor. Assuming a given transaminase accepted 4-DMAB as a substrate, the performance of the enzyme with a range of amino donor substrates could be evaluated, by testing biotransformations for the presence of residual 4-DMAB, which would react with added indole to give the same bis(indolyl)methane product (3) (Scheme 2). In this case, lower absorbance values would be indicative of better acceptance of the amine donor by the enzyme.

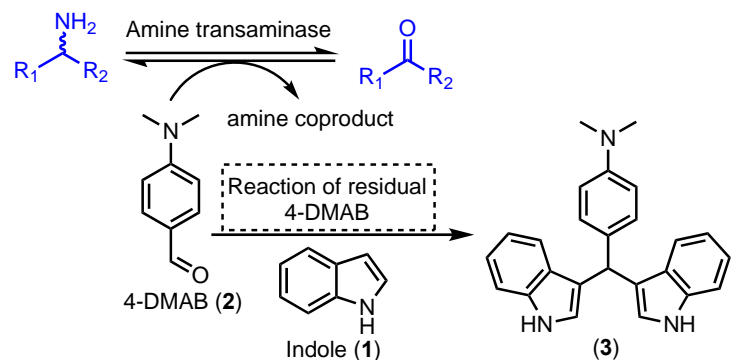

Scheme 2. Strategy for screening amine donors by exploiting 4-DMAB as the acceptor.

The assay was performed using commercially available $(S)$ selective ATA-256, (S)-MBA and 4-DMAB, and monitored at various points over a $24 \mathrm{~h}$ period (Figure 2 ). The reactions were developed using a combination of indole and $\mathrm{HCl}$ and interestingly, exposure to light accelerated color formation (see SI for details). As the biotransformation incubation time increases (A-G across plate 1), there is a clear decrease in color intensity, due to a decrease in the concentration of residual 4-DMAB available to react with the added indole. Indole standards were run alongside the biotransformations each time and used to generate a standard curve. The spectrophotometrically predicted values correlated well with conversions measured independently on the GC (Table 3) at both low and high conversions.

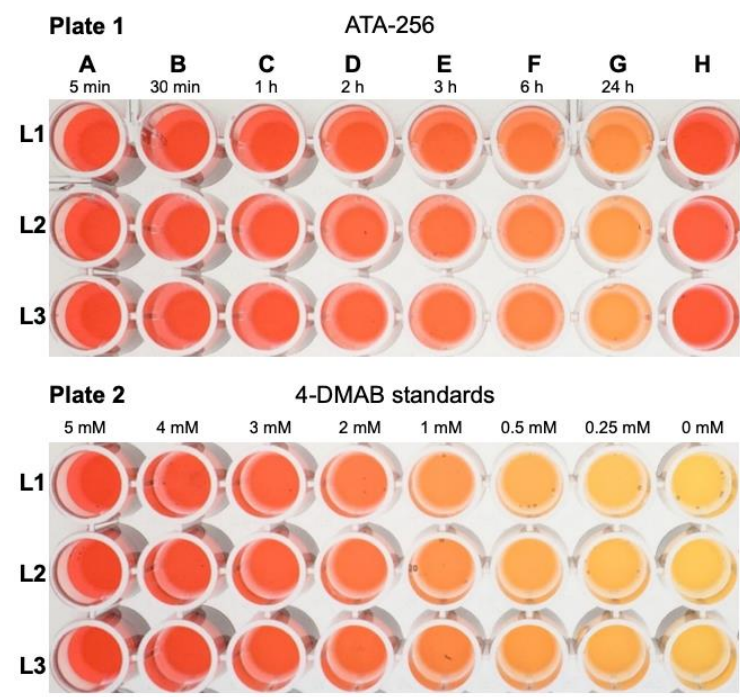

Figure 2. Donor screen. Plate 1: biotransformations with (S)-MBA (5 mM), 4 DMAB $(5 \mathrm{mM})$ and ATA-256 $(1 \mathrm{mg} / \mathrm{mL})$, monitored over 24 hours, and developed using Ehrlich's reagent. $\mathbf{H}=$ no enzyme control. Plate 2: 4-DMAB standards with enzyme omitted. L1-3 are replicates.

Table 3. Donor screen: conversion of (S)-MBA (5 mM) to acetophenone (5) in the presence of 4-DMAB $(5 \mathrm{mM})$ and ATA-256, HEPES $(100 \mathrm{Mm}, \mathrm{pH} 7.5), 30^{\circ} \mathrm{C}$

\begin{tabular}{cccc}
\hline Entry & $\begin{array}{c}\text { Reaction } \\
\text { time }\end{array}$ & $\begin{array}{c}\text { Abs. } \\
\% \text { conv. }\end{array}$ & $\begin{array}{c}\text { GC } \\
\% \text { conv. }\end{array}$ \\
\hline ATA-256 & & & \\
$\mathbf{1}$ & $6 \mathrm{~min}$ & $<5$ & $<5$ \\
$\mathbf{2}$ & $30 \mathrm{~min}$ & 14 & 14 \\
$\mathbf{3}$ & 1 hour & 27 & 23 \\
$\mathbf{4}$ & 2 hours & 41 & 40 \\
$\mathbf{5}$ & 3 hours & 51 & 54 \\
$\mathbf{6}$ & 6 hours & 67 & 65 \\
$\mathbf{7}$ & 24 hours & 78 & 82
\end{tabular}

$\mathrm{GC}$ conversion is based on the disappearance of (S)-MBA and the accumulation of acetophenone. See SI for details.

Six WT ATAs ${ }^{[19]}$ were selected to demonstrate that the same assay can also be employed to screen libraries of transaminases in order to determine their enantio-preference. Figure 3 shows biotransformations with three $(R)$ - and three $(S)$-selective ATAs in the presence of 4-DMAB and both $(R)$-MBA and (S)-MBA. $\mathrm{HEWT}^{[19 \mathrm{a}]}$ and $\mathrm{CV}^{[19 \mathrm{~b}]}$ show high conversions with $(S)-\mathrm{MBA}$ of $81 \%$ and $80 \%$ respectively (Table 4 ), and the decrease in colour is visually apparent in the wells and quantitatively measurable spectrophotometrically. Significantly lower conversions were achieved with the other ATAs but are still measurable using this assay. As before, the UV predicted conversion compare well with those measure by GC, even at low conversions (Table 4).

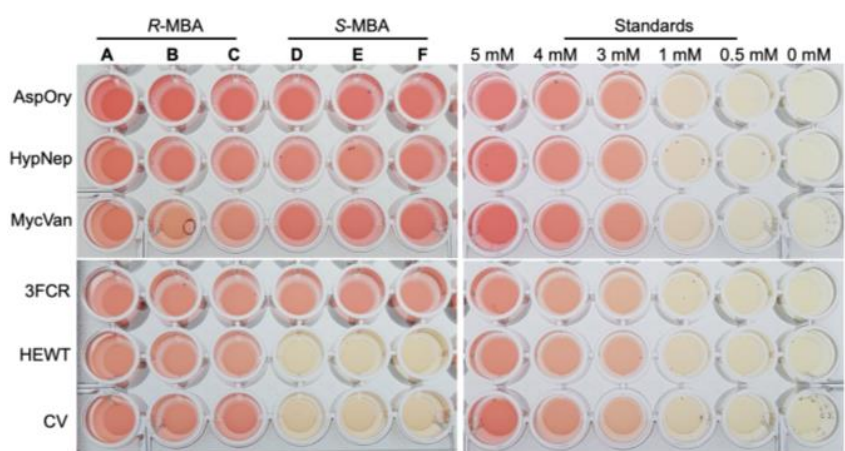

Figure 3. Enantiopreference screen. biotransformations with $(R)$ - or $(S)$-MBA ( $5 \mathrm{mM}), 4-\mathrm{DMAB}(5 \mathrm{mM})$, cell lysate (50uL), $24 \mathrm{~h}$, and developed using Ehrlich's reagent. Reactions are performed in triplicate. Standards contain 4-DMAB (5 $\mathrm{mM}$ ) and varying concentrations of (S)-MBA (enzyme omitted). See SI for details.

Table 4. Enantio-preference screen: conversion of $(R)$ - or $(S)$-MBA $(5 \mathrm{mM})$ to acetophenone in the presence of 4 -DMAB $(5 \mathrm{mM}), \mathrm{Kpi}(100 \mathrm{mM}, \mathrm{pH} 8), 30^{\circ} \mathrm{C}$ determined by colorimetric assay and GC-FID

\begin{tabular}{ccccc}
\hline Enzyme & $\begin{array}{c}(R)-\mathrm{MBA} \\
\text { Abs. } \\
\% \text { conv. }\end{array}$ & $\begin{array}{c}(R)-\mathrm{MBA} \\
\text { GC } \\
\% \text { conv. }\end{array}$ & $\begin{array}{c}(S) \text {-MBA } \\
\text { Abs. } \\
\% \text { conv. }\end{array}$ & $\begin{array}{c}(S)-\mathrm{MBA} \\
\text { GC } \\
\% \text { conv. }\end{array}$ \\
\hline AspOry & $<1$ & $<1$ & $<1$ & $<1$ \\
HypNep & 10 & 7 & 6 & nd \\
MycVan & 28 & 27 & 4 & $<1$ \\
3FCR & Nd & $<1$ & 3 & 9 \\
HEWT & $<1$ & $<1$ & 73 & 81 \\
CV & $<1$ & $<1$ & 70 & 80
\end{tabular}

GC conversion is based on the disappearance of starting material. See SI for details. nd=not detected. See Table S1 for information on standard deviation values.

In order to expand the utility of this assay, we sought to develop a colony-based screen which would enable large variant libraries to be evaluated in a high-throughput manner. However, indole is produced endogenously in indole-positive bacteria by the 
action of the enzyme tryptophanase (EC 4.1.99.1), which hydrolytically cleaves tryptophan to give indole, pyruvate and ammonia. ${ }^{[20]}$ In $E$. coli (an indole-positive bacterium), including the commonly used expression strain BL21(DE3), the enzyme is encoded by the gene tnaA. ${ }^{[21]}$ Initial studies showed that it was not possible to distinguish indole generated via this pathway from indole produced as a coproduct in the biotransformation with 2AEA as the donor. To enable the use of this expression strain for library generation and high-throughput screening, it was first necessary to remove the tryptophanase activity from the host strain. The in-frame gene deletion method of Link et al. ${ }^{[22]}$ was employed, whereby the gene open reading frame is removed in its entirety, minimising the likelihood of polar effects on other genes in the operon, and ensuring no antibiotic resistance marker remains. The latter means that any protein expression plasmid may be subsequently used for the generation of variant transaminase libraries.

The reagent, p-dimethylaminocinnamaldehyde (DMACA), ${ }^{[23]}$ was employed as an alternative to DMAB during solid-phase assay development (Figure 4). To eliminate interference from endogenous pyruvate produced within the bacterial cells, a pre-incubation step was performed. ${ }^{[2]}$ When cells were exposed to the amine donor (2-AEA), but without addition of external pyruvate substrate, BL21(DE3) colonies rapidly turned blue (Plate 1 ), while $\mathrm{BL21}(\mathrm{DE} 3) \Delta$ tnaA remained pink. Only in the presence of the pyruvate substrate did the $\triangle$ tnaA colonies turn blue, due to the production of the indole coproduct, which reacts with Ehrlich's reagent (Plate 2). After 1-hour incubation (Plates $3 \& 4$ ), no significant background was evident in the KO strain. These results demonstrate the power of this solid-phase assay for the high-throughput screening of large TA libraries using this novel expression strain.

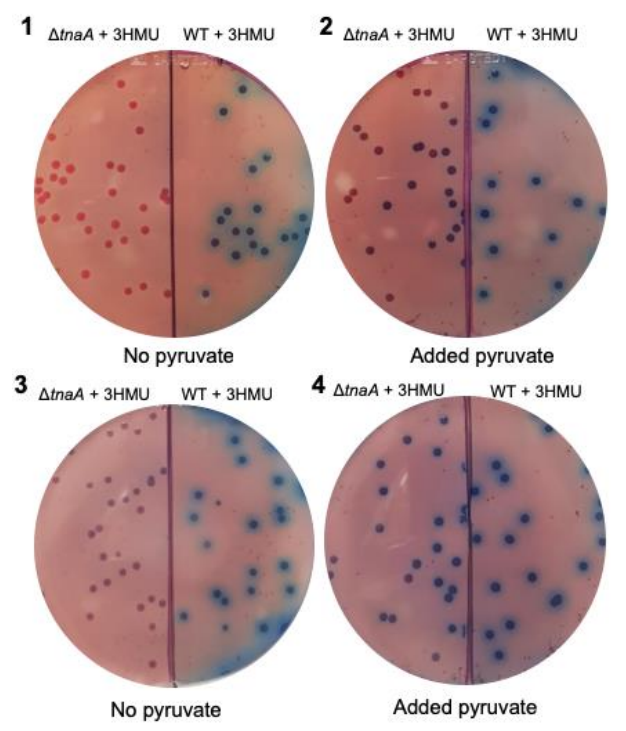

\section{Acknowledgements}

We thank Prof. David Summer from the University of Cambridge for supplying the control E. Coli BW25113 strains ( $\Delta$ tnaA:kan and wild-type). We are grateful to Prof. Francesca Paradisi and Prof. Uwe Bornscheuer for supplying plasmid DNA for the noncommercial enzymes used in this study and to Mr. Jonathan Hunter, School of Chemistry, Nottingham for carrying out the light measurement. Research leading to these results has received
Figure 4. High-throughput solid-phase screen employing the E. coli BL21(DE3) $\triangle$ tnaA tryptophanase knock-out strain, alongside BL21(DE3). 1) 2-AEA (11 $\mathrm{mM}), 30 \mathrm{~min}$ incubation at r.t. 2) 2-AEA (11 mM), pyruvate $(10 \mathrm{mM}), 30 \mathrm{~min}$ incubation 3) 2-AEA (11 mM), $1 \mathrm{~h}$ incubation at r.t. 4) 2-AEA (11 mM), pyruvate $(10 \mathrm{mM}), 1 \mathrm{~h}$ incubation at r.t. See SI for details.

In summary, we have developed a comprehensive and simple assay for amine transaminases, which enables rapid spectrophotometric identification of enzymes with activity towards both novel amine donor and acceptor substrates, as well as allowing the enantio-preference of the biocatalysts to be profiled. The screen relies on the reaction of in situ produced or exogenously added indole with Ehrlich's reagent and its derivatives and has been demonstrated to work with both commercially available ATAs as well as wild-type enzymes. An engineered expression strain lacking tryptophanase activity, E. coli BL21(DE3) $\Delta$ tnaA, has also been developed, and the strain used to design a colony-based solid-phase screen. This strain will be made freely available to academic and industrial teams who wish to carry out library screening. The assay has potential to simplify and expedite directed evolution of ATAs, particularly in the absence of expensive robotics platforms, and become the screening method of choice for the identification of novel substrates.

\section{Experimental \\ Acceptor screen}

The colorimetric screen was performed by adding a sample of the biotransformation $(10 \mu \mathrm{L})$ to a well containing $90 \mu \mathrm{L}$ of a mixture of DMSO: $\mathrm{H}_{2} \mathrm{O} / 9: 1$ and mixed thoroughly. To this was added 100 $\mu \mathrm{L}$ of a solution of $p$-dimethylaminobenzaldehyde $(0.67 \mathrm{M}$ in $\mathrm{EtOH}: \mathrm{HCl}(1: 1))$ and the solution was mixed thoroughly. The colour was allowed to develop for 30 minutes and a spectral scan of the plate was performed on an EPOCH 2 microplate reader (BioTek Instruments) from $470-600 \mathrm{~nm}$. The maximum absorption was recorded as $572 \mathrm{~nm}$.

\section{Donor screen}

The colorimetric screen was performed by diluting the biotransformations $(40 \mu \mathrm{L})$ in biotransformation buffer $(160 \mu \mathrm{L})$. $50 \mu \mathrm{L}$ of the resulting solution was transferred to a well containing indole ( $50 \mu \mathrm{L}, 50 \mathrm{mM}$ in DMSO) and mixed thoroughly. To this was added $\mathrm{DMSO} / \mathrm{HCl}(100 \mu \mathrm{L}, 1: 1(\mathrm{v} / \mathrm{v}))$ and the solution was mixed thoroughly. The colour was developed for 8 minutes under white light. A spectral scan of the plate was then performed on an EPOCH 2 microplate (BioTek Instruments) reader from 500-530 $\mathrm{nm}$. The maximum absorption was recorded at $518 \mathrm{~nm}$.

funding from the BBSRC (BB/M021947/1), the BBSRC Doctoral Training Programme BBSRC DTP (UK) [grant number BB/M008770/1], the EPSRC Centre for Doctoral Training in Sustainable Chemistry (grant number EP/L015633/1) and the University of Nottingham.

Keywords: biocatalysis $\bullet$ chiral amine $\cdot$ high-throughput screen $\bullet$ indole $\cdot$ transaminase 
[1] a) H. Kohls, F. Steffen-Munsberg, M. Höhne, Curr. Opin. Chem. Biol. 2014, 19, 180; b) A. Gomm, E O'Reilly, Curr. Opin. Chem. Biol. 2018, 43,106; c) G. Grogan, Curr. Opin. Chem. Biol. 2018, 43, 15; d) N. J. Turner, E. O'Reilly, Nat Chem. Biol. 2013, 9, 285; e) A. P. Green, N. J. Turner, Perspect. Sci. 2016, 9, 42; f) M. Hönig, P. Sondermann, N. J. Turner, E. M. Carreira, Angew. Chem. Int. Ed. 2017, 56, 8942; Angew.Chem. 2017, 129, 9068.

[2] a) F. H. Arnold, Angew. Chem. Int. Ed. 2018, 57, 4143; Angew. Chem. 2018, 130,4212 ; b) N. J. Turner, Nat. Chem. Biol. 2009, 5, 567; c) S. C. Hammer, A. M. Knight, F. H. Arnold, Curr. Opin. Green. Sus. Chem. 2017, 7 23; d) C. A. Denard, H. Ren, H. Zhao, Curr. Opin. Chem. Biol., 2015, 25, 55; e) U. T. Bornscheuer, G. W. Huisman, R. J. Kazlauskas, S. Lutz, J. C. Moore, K. Robins, Nature, 2012, 485, 185.

[3] a) C. Zeymer, D. Hilvert, Annu. Rev. Biochem. 2018, 87, 131; b) J. L. Porter, R. A. Rusli, D. L. Ollis, Chembiochem, 2016, 17,197; c) M. T. Reetz in Directed Evolution of Selective Enzymes, Wiley-VCH Verlag GmbH \& Co.

\section{$\mathrm{KGaA}, 2016$}

[4] J-P. Goddard, J.-L. Reymond, Curr. Opin. Biotech. 2004, 15, 314; b) M. S. Packer, D. R. Liu, Nat. Rev. Genet. 16, 379; c) H. Xiao, Z. Bao, H. Zhao, Ind Eng Chem Res. 2015, 54, 4011.

[5] Frances H. Arnold shared the Nobel Prize in chemistry in 2018 for "for the directed evolution of enzymes" https://www.nobelprize.org/prizes/chemistry/2018/press-release/.

[6] a) F. Guo, P. Berglund, Green Chem, 2017, 19, 333; b) I. Slabu, J. L. Galman, R. C. Lloyd, N. J. Turner, ACS Catal. 2017, 7, 8263; c) N. J. Turner and M. D. Truppo in Chiral Amine Synthesis: Methods, Developments and Applications (T. C. Nugent), Wiley-VCH, Weinheim, 2010, pp. 431; d) M. Höhne, U. T. Bornscheuer, ChemCatChem 2009, 1, 42.

[7] a) C. K. Savile et al., Science 2010, 329, 305; b) M. Voss, D. Das, M. Genz, A. Kumar, N. Kulkarni, J. Kustosz, P. Kumar, U. T. Bornscheuer, M. Höhne, ACS Catal. 2018, 8, 11524; c) M. S. Weiß, I. V. Pavlidis, P. Spurr, S. P. Hanlon, B. Wirz, H. lding, U. T. Bornscheuer, Org. Biomol. Chem. 2016, 14 10249; d) I. V. Pavlidis, M. S. Weiß, M. Genz, P. Spurr, S. P. Hanlon, B. Wirz, H. Iding, U. T. Bornscheuer, Nat. Chem. 2016, 8, 1076; e) T. Börner, S.

Rämisch, S. Bartsch, A. Vogel, P. Adlercreutz, C. Grey, ChemBioChem. 2017, $18,1582$.

[8] M. Bommer, J. M. Ward, Enzyme. Microb. Technol. 2013, 52, 218.

[9] J. Hopwood, M. D. Truppo, N. J. Turner, R. C. Lloyd, ChemComm. 2011, $47,773$.

[10] S. Schätzle, M. Höhne, E. Redestad, K. Robins, U. T. Bornscheuer, Anal. Chem. 2009, 81, 8244.

[11] T. Scheidt, H. Land, M. Anderson, Y. Chen, P. Berglund, D. Yi, W-D.

Fessner, Adv. Syn. Cat. 2015, 257, 1721.
[12] a) T. Sehl, R. C. Simon, H. C. Hailes, J. M. Ward, U. Schell, M. Pohl, D. Rother, J.Biotechnol 2012, 159, 188; b) M. Bommer, J. M. Ward, 2016, 493, 8; c) D. Baud, N. Ladkau, T. S. Moody, J. M. Ward, H. C. Hailes, 2015, 51, 17225. d) M. S. Weiss, I. V. Pavlidis, C. Vickers, M. Höhne, U. T.

Bornscheuer, Anal. Chem. 2014, 86, 23, 11847-11853.

[13] A. P. Green, N. J. Turner, E. O'Reilly, Angew. Chem. Int. Ed. 2014, 53, 10714; Angew. Chem. 2014, 126, 10890.

[14] A. Gomm, S. Grigoriou, C. Peel, J. Ryan, N. Mujtaba, T. Clarke, E. Kulcinskaja, E. O'Reilly, Eur. J. Org. Chem. 2018, 38, 5282

[15] A. C.Lamb, R. A.Federico-Perez, Z-L. Xue, Anal. Biochem. 2015, 484, 21 b) G. L. Lombard, V. R. Dowell, J. Clin. Microbiol. 1983, 18, 609. [16] a) P. Ehrlich, Die Med. Woche und Balneol. Cent. 1901, 151. b) V. Hemraj, S. Diksha, G. Avneet, Innovare J. Life Sci. 2013, 1, 1.

[17] a) H. Yatzidis, M. Garidi, C. Vassilikos, D. Mayopoulou, A. Akilas, J. Clin. Pathol. 1964, 17, 163. b) M. Knowlton, F. C. Dohan, H. Sprince, Anal. Chem., 1960, 32, 666

[18] F. Steffen-Munsberg, C. Vickers, A. Thontowi, S. Schätzle, T. Tumlirsch, M. S. Humble, H. Land, P. Berglund, U. T. Bornscheuer, M. Höhne, ChemCatChem, 2012, 5, 150

[19] a) L. Cerioli, M. Planchestainer, J. Cassidy, D. Tessaro, F. Paradisi, J. Mol. Catal. B-Enzym. 2015, 120, 141; b) U. Kaulmann, K. Smithies, M. E. B. Smith, H. C. Hailes, Enzyme and Microb. Technol. 2007, 41, 628 c) M. Höhne, S. Schätzle, H. Jochens, K. Robins, U. T. Bornscheuer, Nat. Chem. Biol. 2010 $6,807$.

[20] W. A. Wood, I. C. Gunsalus, W. W. Umbreit, J. Biol. Chem. 1947, 170, 313.

[21] M. C. Deeley, C. Yanofsky, J. Bacteriol. 1981, 147, 787.

[22] A. J. Link, D. Phillips, G. M. Church, J. Bacteriol. 1997, 179, 6228.

[23] J. M. Miller, J. W. Wright, J. Clin. Microbiol. 1982, 15, 589.

[24] M. Planchestainer, E. Hegarty, C. M. Heckmann, L. J. Gourlay and F. Paradisi, Chem. Sci., 2019, 10, 5952. 
